\title{
DESIGN AND DEVELOPMENT OF GRID TIE INVERTER WITH CLOSED LOOP SPWM SINGLE STAGE THREE SWITCH SYNCHRONIZED AND BUCK-BOOST PRINCIPLE
}

\author{
Ambika Naik ${ }^{1}$, Praveen Naik ${ }^{2}$, Uttam Sattpute $^{3}$ \\ ${ }^{I}$ Electronics \& Communication, VDRIT, Karnataka, India \\ ${ }^{2}$ Assistant Professor, Computer Science, AIT, Karnataka, India \\ ${ }^{3}$ Assistant Professor, Electrical \& Electronics, VDRIT, Karnataka, India
}

\begin{abstract}
The project aims the devise topology of single stage, three switch, closed loop SPWM control photovoltaic inverter for grid tie residential application. Predictable buck-boost GTI used in photovoltaic application are of manifold stage inverter systems, encompass dc-ac-dc converters added to achieve a raised dc voltage before inversion. Additional stage require more power machinery and also more power loss results, Even though a two-stage buck-boost inverter can reach significantly high power capability, which introduces circuit density as well as adds up the cost. In disparity with existing system project proposes the intend of a three-switch single stage grid connected buck-boost inverter, where switching losses to a great extent reduced as number of switches and also flyback, buck boost function principles are applied to match up with solar energy accessibility variation. For switching power circuit blend of square wave and SPWM is used, with kind of combination switching frequency reduces to such a level where switching losses significantly reduced. To realize Grid synchronization Strategy sine wave beginning from grid will be used as orientation signal for SPWM. To regulate inverter immediate ac output closed loop control scheme is engaged. Implementation of simple controller format with which output is stabilized as fast as probable. Advantages of this method are established by simulation of a grid-connected single-stage three switch, closed loop SPWM buck-boost inverter..
\end{abstract}

Keywords: GTI, Buck-Boost, SPWM, and Square wave etc...

\section{INTRODUCTION}

Growing energy burning up around the globe, eminent exhaustion of fossil fuel reserves and effects of global warming has escort the a great interest on alternative energy sources. There is obligation of research on alternative renewable energy system due to the threat of electrical energy rationing, blackouts, and over taxes in addition to the environment awareness. Solar energy is measured as one of the best alternative to the electricity generation because of its own advantages of easy availability, cleanliness, easy installation and lower preservation. so solar power is increasingly being used in grid connected system to feed low carbon energy to the grid.[1]

\section{PROPOSED SYSTEM}

Conventional buck-boost GTI used in photovoltaic application are of multiple stage inverter systems, have dcac-dc converters added to achieve a raised dc voltage before inversion. Additional stage require more power components also more power loss results, Although a two-stage buckboost inverter can reach noticeably high power capacity, which introduces circuit complexity as well as adds up the cost. In contrast with existing system project proposes the invent of a three-switch single stage grid connected buckboost inverter, where switching losses greatly reduced as number of switches and also flyback, buck boost operation principles are applied to go with solar energy availability variation. Proposed work is intended to begin a simple yet effective control method for such of single stage, three switch, closed loop SPWM control photovoltaic inverter for grid tie residential application Topology has plentiful rewards like compact size, low losses, high efficiency, effective utilization of solar array, simpler control, low cost. For switching power circuit combination of square wave and SPWM is used, with kind of blend switching frequency reduces to such a level where switching losses considerably reduced. Grid synchronization strategy where sine wave beginning from grid will be used as reference signal for SPWM.[2][4]

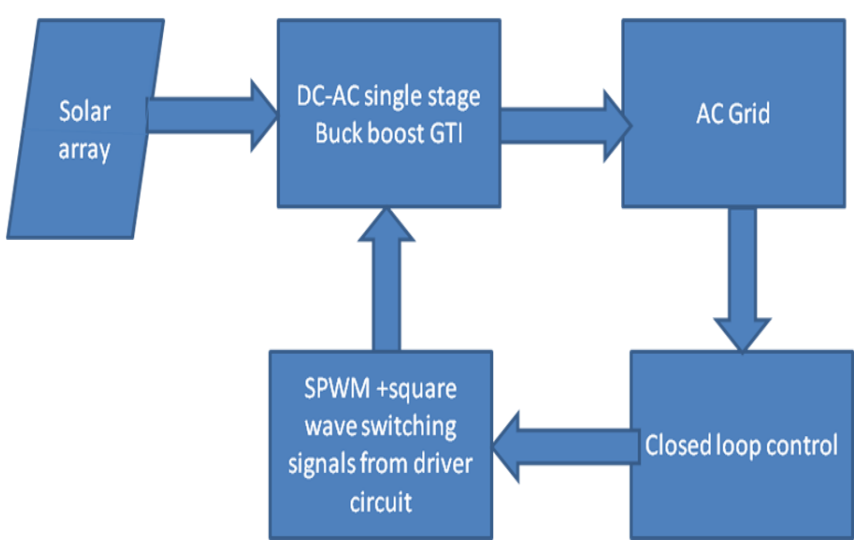

Fig-1: Block diagram of proposed GTI system 


\section{DESIGN AND IMPLEMENTATION OF GTI}

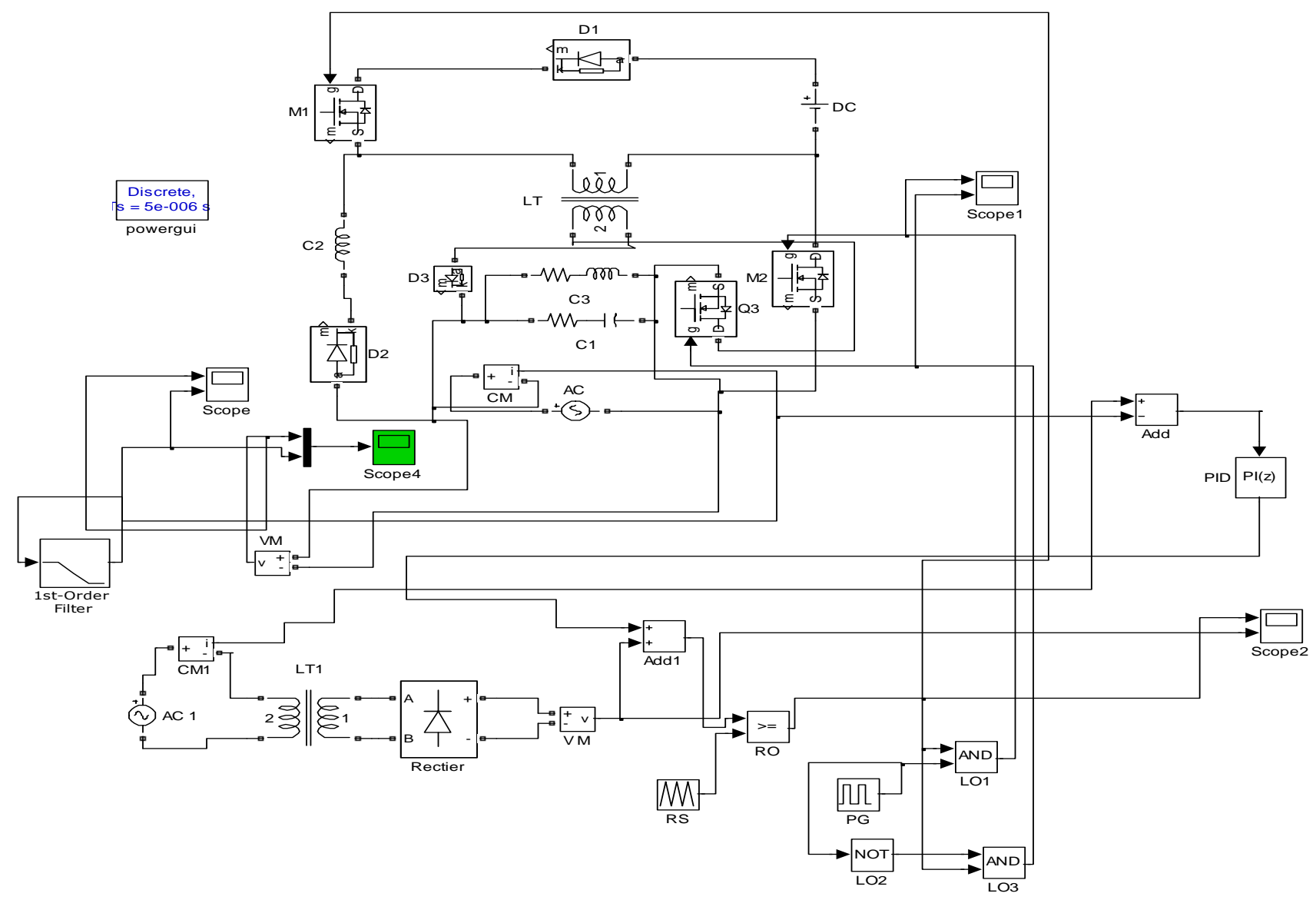

Fig -2: simulation module for GTI system

\subsection{Power Circuit Design}

The projected single-stage grid-connected buck-boost inverter power circuit configuration consists of three MOSFET switches Q1, Q2, and Q3, three diodes, DI, D2, and D3, two coupled inductors L1, L2 and a capacitor C. The two coupled inductors which is used to transfer energy beginning the input PV array dc face to the utility grid, have identical inductance $\mathrm{L}$ and equal turns. Inductor is forever connected with charging and discharging circuit Since only one switch is turned $\mathrm{ON}$ in every status The inverter action can be separated keen on: charge and discharge process working in the (1) positive half cycle and (2) negative half cycle.

\section{Positive Half Cycle}

Switch Q3 is for all time excluded in the positive half cycle of the inverter. The inverter operation in the positive half cycle can be divided into:

(1) Charging state

(2) Discharging state.

During charging state in positive half cycle, the switches Q2 and Q3 are turned off, and the switch Q1 is turned on to charge the inductor L1 through the diode D2. At that time the capacitor allows incessant current to the load.

During discharging state, the switches Q1 and Q3 are turned off, and energy that was stored in inductor, LI discharged through the switch Q2, to the destination i.e grid utility

\section{Negative Half Cycle}

Switch Q2 is forever excluded the negative half cycle condition of the inverter. while the inverter works in negative half cycle, its purpose can be further divide into:

(3) Charging state

(4) Discharging state.

During charging state in the negative half cycle, the switches Q2 and Q3 are turned off, and the switch QI is turned ON to charge the inductor LI via diode DI. At that state capacitor allows unremitting current to load.

During discharging state, the switch Q1 and Q2 are turned off and the switch Q3 is turned on. The stocked energy in L will be discharge to the coupled inductor L2 which discharge to the load via switch Q3 and diode D3. [3][4] 


\subsection{Control Circuit Design}

In this proposed design instead of using one type of switching signal to switch the inverter as in conformist inverter design, a combination of square wave and SPWM is in job. With this kind of combination switching, the switching loss across the switches of the inverter will be wholly reduced. As only one switch is operating at one time. To achieve the synchronizing course, the sine wave of Utility itself will be sampled and taken as reference .from power grid the voltage transformer to step down $220 \mathrm{~V}$ grid voltage into $5 \mathrm{~V}$. The same samples are used to generate SPWM signal. Thus the frequency of the output from the GTI will be having the same frequency as the grid voltage and current where this is one of the most major obligation for the GTI .After sampling, the sine wave is rectified with a precision rectifier. In addition, a high frequency triangle wave of $10 \mathrm{KHz}$ frequency is used

\subsection{Closed-Loop Control}

The slip in between the measured output current and the reference current is recompense by a Proportional Integral (PI) controller and is used to cause the desired SPWM switching gate signals for MOSFET Q1 Q2 and Q3. In this closed-loop operation originally we work out the peak modulation index Ma for $50 \mathrm{~Hz}$ grid voltage cycle by using of equation (1) and then this peak value is used to produce the sinusoidal modulation index. In this proposed GTI design, closed-loop controller idea where the output current is measured and compared by means of an ac reference current.[4]

\subsection{Main Concern of GTI}

The output voltage from GTI is essential to meet certain circumstances for the inverter to be associated to the grid.[2]

- Voltage magnitude and phase of inverter must be same as grid.

- $\quad$ The GTI output frequency must equal with the grid frequency $(50 \mathrm{~Hz}$ in India)

\section{MATHMATICAL MODULE}

Let Input PV array voltage $=24 \mathrm{v}$

Vrms $=220 \mathrm{v}$

Pout $=600 \mathrm{w}$

Switching frequency $=10 \mathrm{KHz}$

Coefficient factor for inverter $\mathrm{k}=3.2$

\subsection{Modulation Index}

Hence modulation index can be calculated by the equation

$$
\begin{aligned}
& M=\frac{\sqrt{2}(\text { Vrms })}{\sqrt{2} \text { Vrms }+ \text { Vdc }} . \\
& M=\frac{\sqrt{2(220)}}{\sqrt{2(220)}+24}=93 \%
\end{aligned}
$$

\subsection{Coupled Inductor Selection}

For a grid-connected inverter a simple critical method, to determine the inductance value. The value of coupled inductance, L for DCM operation is calculated by using following equation.[7]

$$
\mathrm{L}=\frac{M V d c^{2}}{4 P s w f}=\frac{0.93 * 24^{2}}{4 * 600 * 10000}=20 \mu \mathrm{H}
$$

\subsection{Filter Inductor Selection}

In order to limit the current ripple a filter inductor used in the inverter circuit. inductance value of the inductor can be expressed $F l$

$$
\begin{gathered}
F l=\frac{1}{\Delta I * s w f *\left(\frac{1}{V d c}\right) *\left(\frac{1}{V \text { out }}\right)} \ldots \ldots \ldots \ldots \ldots \ldots \ldots . . .(3) \\
F l=\frac{1}{0.02 * 10 k *\left(\frac{1}{24}\right) *\left(\frac{1}{\sqrt{2} * 220}\right)}=115 \mu \mathrm{H}
\end{gathered}
$$

\subsection{Output Capacitor Selection}

The average differential equation for output filter capacitor is specified below. The output filter capacitor is responsible for desire ripple voltage, ripple current and stability. Equation can be solved by taking D as $93 \%$ and cut-off frequency as $50 \mathrm{~Hz}$

$$
\frac{d V c}{D t} C=(1-D) I \frac{\text { Vout }}{R}
$$

$C$ approximately $=10 \mathrm{mF}$

\subsection{Output Current}

Considering that the resistance of coupled inductor, switches and diodes are negligible and the inverter is worked at DCM; the output current Iout of the inverter can be expresses by using following equation

$$
\begin{aligned}
& \text { Iout }=\frac{T * K^{2} V d c^{2}}{2 \sqrt{2 L}} \sin w t \ldots \ldots \ldots \ldots \ldots \ldots \ldots . .(5) \\
& =\frac{\left(\frac{1}{1000}\right) * 3.2 * 24^{2}}{2 \sqrt{220 m H}} \sin w t=10.5 \text { sinwt }
\end{aligned}
$$

The module designed is simulated for different level of input source voltages from $12 \mathrm{~V}$ dc to IOOV dc as if it were from a PV panel and results are acknowledged. 


\section{RESULT AND ANALYSIS}

The module designed is simulated for different level of input source voltages from $12 \mathrm{~V}$ dc to IOOV dc as if it were from a PV panel and results are acknowledged

\subsection{Output of Control Circuit}

The three sets of switching signals can be categorized in three groups. The first group contains MOSFETs Q1, while the second group contains MOSFETs Q2 and the third group contains MOSFETs Q3. The resulting switching gate pulses of the inverter power circuits from control circuit are illustrated in Fig. 3, Fig. 4

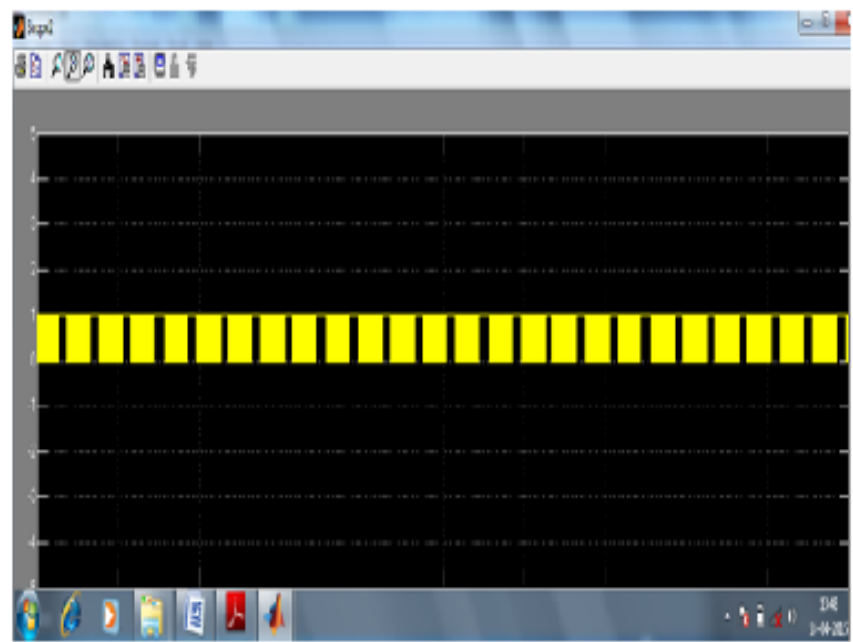

Fig.- 3: Switching gate pulse for MOSFET Q1

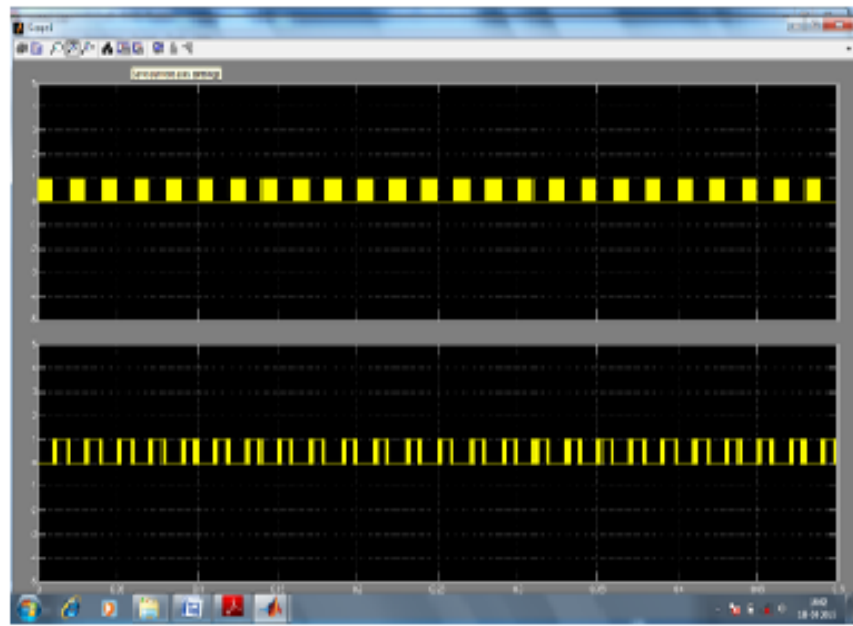

Fig.- 4: Switching gate pulse for MOSFET Q2 \& Q3

\subsection{Output of Power Circuit}

The operation of the inverter is simulated for different level of input source voltages from $12 \mathrm{~V}$ dc to IOOV dc, as if it were from a PV panel. Fig. 5 shows the sinusoidal ac output voltage waveform that is $220 \mathrm{Vrms}$ and $50 \mathrm{~Hz}$ after tied the inverter to the grid. Fig. 5 represents the simulation result of grid-connected power converter, where we observed that both the output current and voltage are in same phase. simulation result of the GTI Output current is at $600 \mathrm{~W}$ when the input voltage is $24 \mathrm{~V} \mathrm{dc}$. Fig.5. represents the simulation result of grid-connected power converter, where we observed that both the output current and voltage are in same phase.

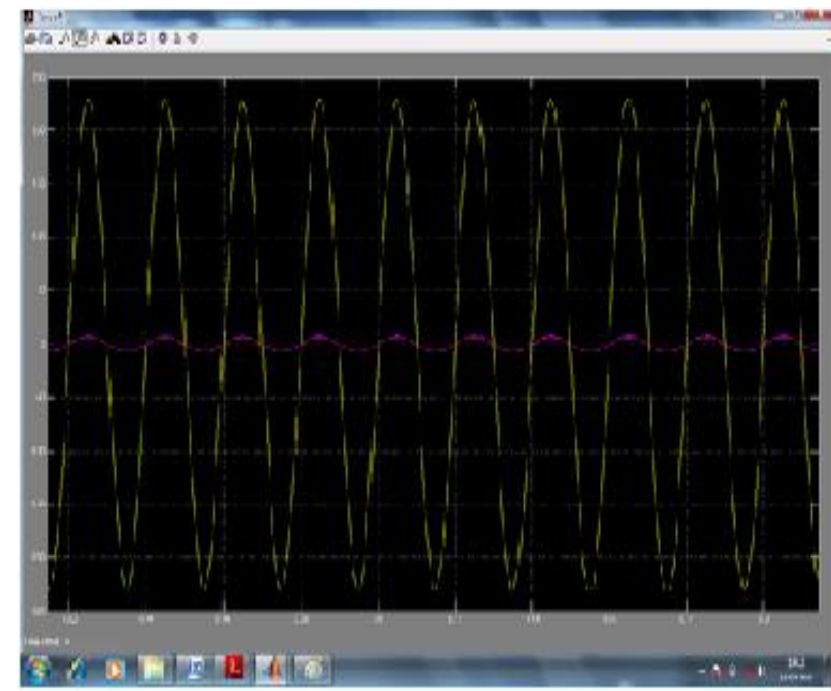

Fig -5: Simulation result of proposed GTI system.

\subsection{THD of GTI Current}

It is observed that the Total Harmonic Distortion (THD) of output current is about $0.9 \%$ which is acceptable.

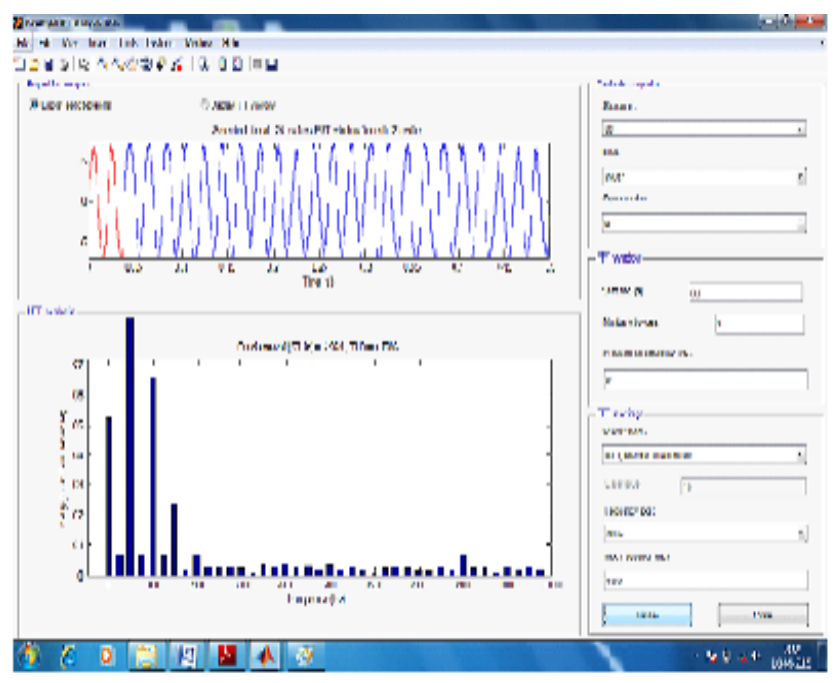

Fig.- 6 Output current THD of GTI

Table -1: Summary simulation results

\begin{tabular}{|l|l|l|l|l|l|}
\hline $\begin{array}{l}\text { Vdc } \\
(\text { Volt })\end{array}$ & $\begin{array}{l}\mathrm{L} \\
(\mathrm{mH})\end{array}$ & $\begin{array}{l}\text { L out } \\
(\mathrm{mH})\end{array}$ & $\begin{array}{l}\text { Cout } \\
(\mathrm{Mf})\end{array}$ & $\begin{array}{l}\text { Iout } \\
(\mathrm{A})\end{array}$ & $\begin{array}{l}\text { THD } \\
(\%)\end{array}$ \\
\hline 12 & 5 & 120 & 15 & 14.31 & 1.43 \\
\hline 24 & 20 & 115 & 10 & 14.85 & 1.41 \\
\hline
\end{tabular}




\section{HARDWARE IMPLEMENTATION}

The projected design is implemented with hardware components and voltage is measured across the load of inverter circuit which shown the reading of $240 \mathrm{AC}$.

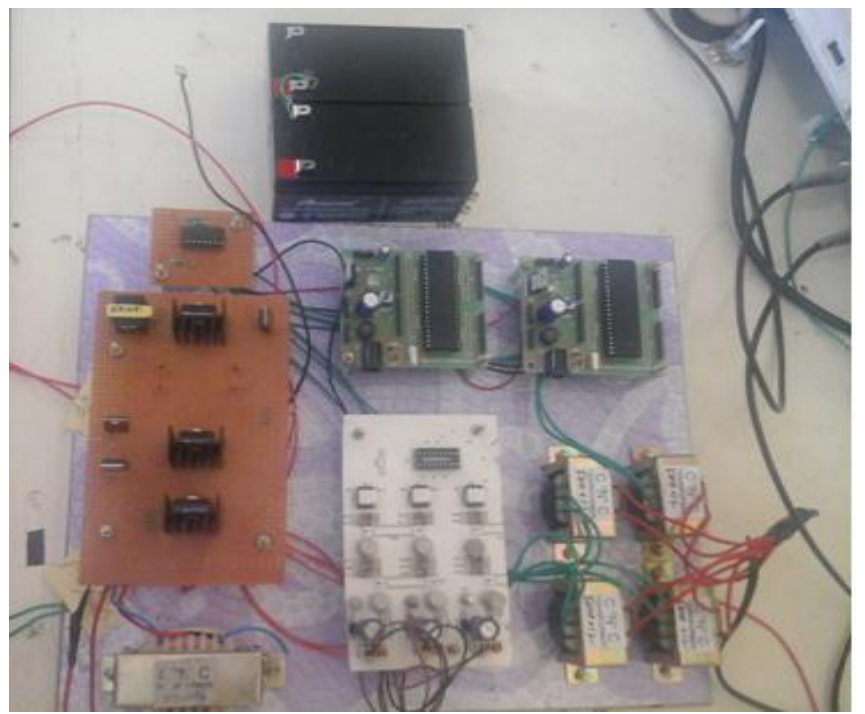

Fig -7: Hardware Implementation for GTI system

\section{CONCLUSION}

Mathematical modeling, analysis of working principle and computer simulation of this proposed single-phase single stage buck-boost GTI is obtainable in this work. Since it uses only three switches, the cost and size of this inverter would also be relatively reduced as compared to the conventional single stage four-switch grid-connected buckboost inverter where at any time two switches will be on. The simulation results revealed the viability of the proposed single stage three-switch buck-boost inverter for grid connected photovoltaic application and established the potential of the inverter to feed a sinusoidal current to the utility grid at a wide range of input photovoltaic dc voltage. The physical fabrication, analysis and test of the proposed grid connected inverter done and implemented Successfully.

\section{FUTURE SCOPE}

Further adoption of a simple control scheme and grid synchronization approach that would make the inverter more reliable. And a strategy is necessary to reduce the complexity in the form of size, control and cost.

\section{REFERENCES}

[1]. Johnson, D. Yoon, and Y. Baghzouz," Modeling and analysis of a bifacial grid- connected photovoltaic system," IEEE Power \& Energy Society General Meeting (PES)., pp. 1-6, July 2012.

[2]. T. K. K wang, S. Masri, " Single phase grid tie inverter for photovoltaic application," in Proc. IEEE Sustainable Utilization and Development in Engineering and Technology C onj, pp. 23-28. Nov 2010.

[3]. P. G. Barbosa, HAC. Braga, M. e.B Rodrigues and E. e. Teixeira, "Boost current multilevel inverter and its application on single-phase grid-connected photovoltaic system," IEEE Trans. Power Electron., vol. 21, no. 4, pp. 1116-1124, July. 2006.

[4]. R.Gonzalez, E.Gubia, 1. Lopez and L. Marroyo, 'Transformerless single phase multilevel-based photovoltaic inverter," IEEE Trans. Ind. Electron., vol. 55, no. 7, pp. 2694-2702, .luI. 2008.

[5]. J. M. Carrasco, L. G. Franquelo, J. T. Bialasiewicz, E. Galván, R. C. Portillo Guisado, M. A. M. Prats, J. I. León, and N.Moreno-Alfonso, "Power-electronic systems for the grid integration of renewable energy sources: A survey,"

[6]. R. L. LaRocca, "Personnel protection devices for use on appliances.

[7]. W. Bower and J. Wiles, "Investigation of ground-fault protection devices for photovoltaic power system applications," in Proc. 28th IEEE Conf.

[8]. E. Gubia, P. Sanchis, A. Ursúa, J. Lopez, and L. Marroyo, "Ground currents in single-phase transformerless photovoltaic systems," Prog. Photovolt.:

[9]. R. González, J. López, P. Sanchis, and L. Marroyo, "Transformerless inverter for single-phase photovoltaic systems.

\section{BIOGRAPHIES}

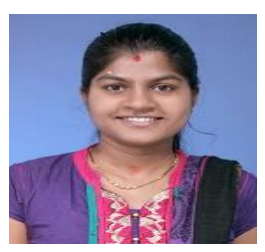

Mrs Ambika Naik is pursuing her masters from VDRIT, Haliyal and Her research interest in the area of Power system Having teaching and industry experience in CAD Design

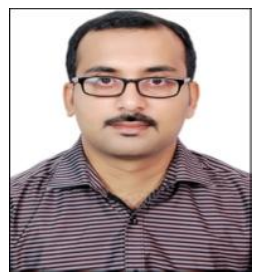

Mr Praveen Naik has received his masters from NMAMIT, Nitte, and he is pursuing his Phd currently in the area of Software Engineering. His other area of interest is in the field of Data mining. Working as an Assistant professor in the department of Computer Science at AIT Bangalore. He has teaching Experience of more than 10 years.

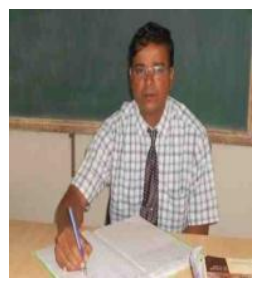

Mr Uttam Sattpute has received Mtech from Basaveshwar Engineering College Bagalkot in Power and Energy System. Pursuing his Phd currently in the area of Power System. Working as an Assistant professor in the department of Electrical and Electronics. He has teaching Experience of more than 12 years. 